\title{
SITUS-SITUS NEOLITIK \\ DI SEPANJANG SUNGAI TASIKMALAYA DAN LEBAK: \\ JEJAK PENUTUR AUSTRONESIA \\ DI PEDALAMAN JAWA BAGIAN BARAT
}

\section{Neolitic Sites around Tasikmalaya and Lebak Rivers: Traces of Austronesian Speakers in West Java}

\author{
Nurul Laili \\ Balai Arkeologi Jawa Barat \\ Jalan Raya Cinunuk Km. 17 Cileunyi, Bandung 40623 \\ E-mail: nurulkarangkajen@gmail.com
}

\begin{abstract}
The purpose of this paper is to reveal the traces of Austronesian speakers in the interior of western Java based on neolithic heritage. Neolithic sites in both Lebak and Tasikmalaya districts are located along the river. This paper focuses on the sites of the research results of the West Java Archaeological Center team in the Cineam and Cibeureum area. The method used is descriptive. The results showed that rivers were the preferred location for neolithic activity.
\end{abstract}

Keywords: neolithic sites, traces, Austronesian

\begin{abstract}
Abstrak
Tujuan tulisan ini akan mengungkap jejak penutur Austronesia di pedalaman di Jawa bagian barat berdasarkan tinggalan neolitik. Situs situs neolitik baik di Kabupaten Lebak dan Kabupaten Tasikmalaya terletak di sepanjang aliran sungai. Tulisan ini menitikberatkan pada situs situs hasil penelitian tim Balai Arkeologi Jawa Barat di Kawasan Cineam, Tasikmalaya dan Kawasan Cibeureum, Lebak. Metode yang digunakan adalah induktif deskriptif. Hasil penelitian menunjukkan bahwa sungai menjadi pilihan untuk lokasi aktivitas neolitik.
\end{abstract}

Kata kunci: situs neolitik, jejak, Austronesia

\section{PENDAHULUAN}

$\mathrm{N}$ eolitik merupakan periode yang ditandai dengan teknologi yang lebih kompleks dari periode sebelumnya. Beliung batu dengan teknologi upam merupakan salah satu produk yang menjadi ciri khas dari periode Neolitik. Selain beliung yang telah diupam, beberapa temuan yang mengindikasikan adanya budaya neolitik adalah peralatan gelang batu dan tembikar (Simanjuntak, 1992). Keberadaan beliung upam sering dikaitkan dengan masyarakat peladang tradisional penutur Austronesia.

Beberapa pernyataan tentang masyarakat Austronesia, ditulis oleh beberapa ahli, di antaranya adalah Bellwood yang menyatakan bahwa migrasi masyarakat penutur Austonesia dari Asia Daratan menuju Asia Tenggara Kepulauan. Masyarakat penutur Austronesia meskipun masih mahir dengan berburu dan mengumpulkan makanan tetapi telah membawa pengetahuan baru berupa pola subsistensi pertanian (Bellwood, 2000; Bellwood, 2007). 
Beberapa penelitian neolitik di Indonesia yang telah dilakukan menunjukkan adanya situs pemukiman dan situs perbengkelan. Beberapa situs neolitik telah dapat diketahui pertanggalan secara absolut. Daerah Sulawesi yaitu Situs Minanga Sipakko, Malawa, Maros, dan Leang Tuwo Mane'e. Keempat situs tersebut memperlihatkan pertanggalan antara 3500- 3800 BP. Adapun daerah Kalimantan Barat di Situs Liang Kawung menunjukkan pertanggalan $3030 \pm 180 \mathrm{BP}$ dan di Situs Nangabalang pertanggalan yang diperoleh $2550 \pm 100$ BP. Kedua situs tersebut salah satu jenis temuannya berupa beliung (Simanjuntak, 2015).

Pertanggalan 3300 BP- 3150 BP dengan produk budaya berupa tembikar berslip merah berasosiasi dengan tulang babi dan moluska ditunjukkan oleh hasil penelitian di Kepulauan Maluku. Adapun pertanggalan 3500 BP dengan produk budaya berupa pecahan tembikar berasosiasi dengan tulang babi diperoleh dari penelitian di Kepulauan Nusa Tenggara dan Timor (Simanjuntak, 2015).

Pertanggalan 1650-800 BC dengan temuan fragmen tembikar bercampur dengan alat serpih obsidian, batu lainnya, dan batu asah merupakan petunjuk neolitik di Pulau Sumatera yaitu di Situs Bukit Arat, Kerinci. Situs lain di Pulau Sumatera yaitu Benua Keling, Pasemah, Sumatera Selatan menunjukkan pertanggalan $1550 \mathrm{BC}$ dengan temuan berupa tembikar polos, beliung, dan tulang manusia (Simanjuntak, 2015).

Pulau Jawa terdapat beberapa situs neolitik, salah satunya berada di Ponjen, Purbalingga, Jawa Tengah. Produk budaya di Ponjen terindikasi sebagai situs perbengkelan dengan temuan berupa gelang dan beliung batu. Pertanggalan di situs tersebut adalah $5570 \pm 210$ BP . Situs lain di Pulau Jawa berada di Song Keplek, Punung, Jawa Timur.
Situs tersebut menunjukkan pertanggalan $3260 \pm 110 \mathrm{BP}$ dengan produk budaya berupa tembikar polos dan beliung(Simanjuntak, 2015). Di Kabupaten Jember juga diperoleh situs neolitik, yaitu Situs Kendenglembu. Situs tersebut menghasilkan produk budaya berupa tembikar slip merah, alat serpih, bilah, beliung paruh, dan belincung dengan pertanggalan $1332 \pm 35$ BP (Noerwidi, S dan Priyatno, Hadi, 2011).

Pergerakan manusia penutur Austronesia menurut Mahirta (2006), berdasarkan penelitian di Kepulauan Indonesia bagian timur, terdapat dua macam pola permukiman prasejarahAustronesia, yaitu (1) permukiman tersebar di sepanjang pantai jika pulau yang dihuni tidak terlalu besar, seperti pulau Kayoa dan Pulau Gebe di Maluku utara, dan (2) permukiman berkembang memanjang ke pedalaman sejajar dengan alur sungai, misalnya situs-situs Kalumpang di Sulawesi Barat dan permukiman tradisional etnis Dayak di Kalimantan (Mahirta, 2006).

Beberapa situs neolitik di Jawa Barat sebagian besar berada di pedalaman dan berada di sepanjang aliran sungai. Situs-situs tersebut diantaranya di Kawasan Cineam Tasikmalaya dan Kawasan Cibeureum di Kabupaten Lebak. Bertolak dengan hal tersebut akan dibahas apa saja ragam temuan serta faktor apa yang melatarbelakangi dipilihnya sungai sebagai lokasi beraktivitas. Metode yang digunakan adalah induktifdeskriptif. Pengetahuan tentang ragam dan pilihan lokasi diharapkan akan mendapatkan informasi tentang aktivitas penutur Austronesia di Jawa bagian barat, khususnya di Kawasan Cineam dan Kawan Cibeureum.

\section{PEMBAHASAN}

Kabupaten Lebak dan Kabupaten Tasikmalaya memiliki banyak potensi 
tinggalan arkeologi, terutama tinggalan yang berkait dengan aktivitas neolitik. Situs-situs neolitik di Kabupaten Lebak dan Kabupaten Tasikmalaya menempati lahan di sepanjang tepian sungai. Sebaran situs- situs neolitik di Kabupaten Tasikmalaya berada di Kawasan Cineam, sedangkan wilayah Kabupaten Lebak, sebaran situs neolitik berada di Kawasan Cibeureum (Gambar 1).

Tinggalan neolitik di Kawasan Cineam diperoleh di Situs Pasirgadung, Blok Makam, Pasirwangi, Sindangsari, Blok Negla, dan Sukabakti. Keseluruhan situs secara lateral berada di sepanjang sungai. Sungai-sungai yang mengaliri Kawasan Cineam yaitu Sungai $\mathrm{Ci}$ Goang dan $\mathrm{Ci}$ Riri. Di kawasan ini, jarak situs dengan sungai kurang dari 500 meter. Di antara sungai tersebut, yaitu $\mathrm{Ci}$ Goang terdapat kandungan batu rijang yang merupakan sumber bahan baku dalam aktivitas neolitik, yaitu pembuatan beliung.
Jarak situs dengan sungai yang terdekat adalah Situs Blok Negla dengan Ci Riri atau juga dikenal sebagai Ci Ampanan berjarak sekitar $50 \mathrm{~m}$. Urutan terdekat berikutnya adalah Situs Sindangsari berjarak 75 meter dengan Ci Goang, Situs Pasirgadung dengan jarak $100 \mathrm{~m}$ dengan Ci Goang, dan Situs Pasirwangi berjarak sekitar $125 \mathrm{~m}$ dari Cigoang. Adapun situs yang terjauh dari sungai adalah Situs Blok makam berjarak $250 \mathrm{~m}$ dengan Ci Goang dan Situs Sukabakti berjarak sekitar $250 \mathrm{~m}$ dengan Ci Ampanan (Ci Riri).

Indikasi adanya aktivitas neolitik tergambar dari temuan yang berupa tinggalan sisa perbengkelan beliung persegi. Artefak yang diperoleh di Situs Pasirgadung berupa bahan baku, hasil produksi, serta limbah dari pembuatan beliung. Ragam temuan di antaranya berupa tatal, serpih, bahan baku, calon beliung, serta beliung jadi. Selain hal tersebut, artefak lain berupa mata panah juga diperoleh di Situs Pasirgadung.

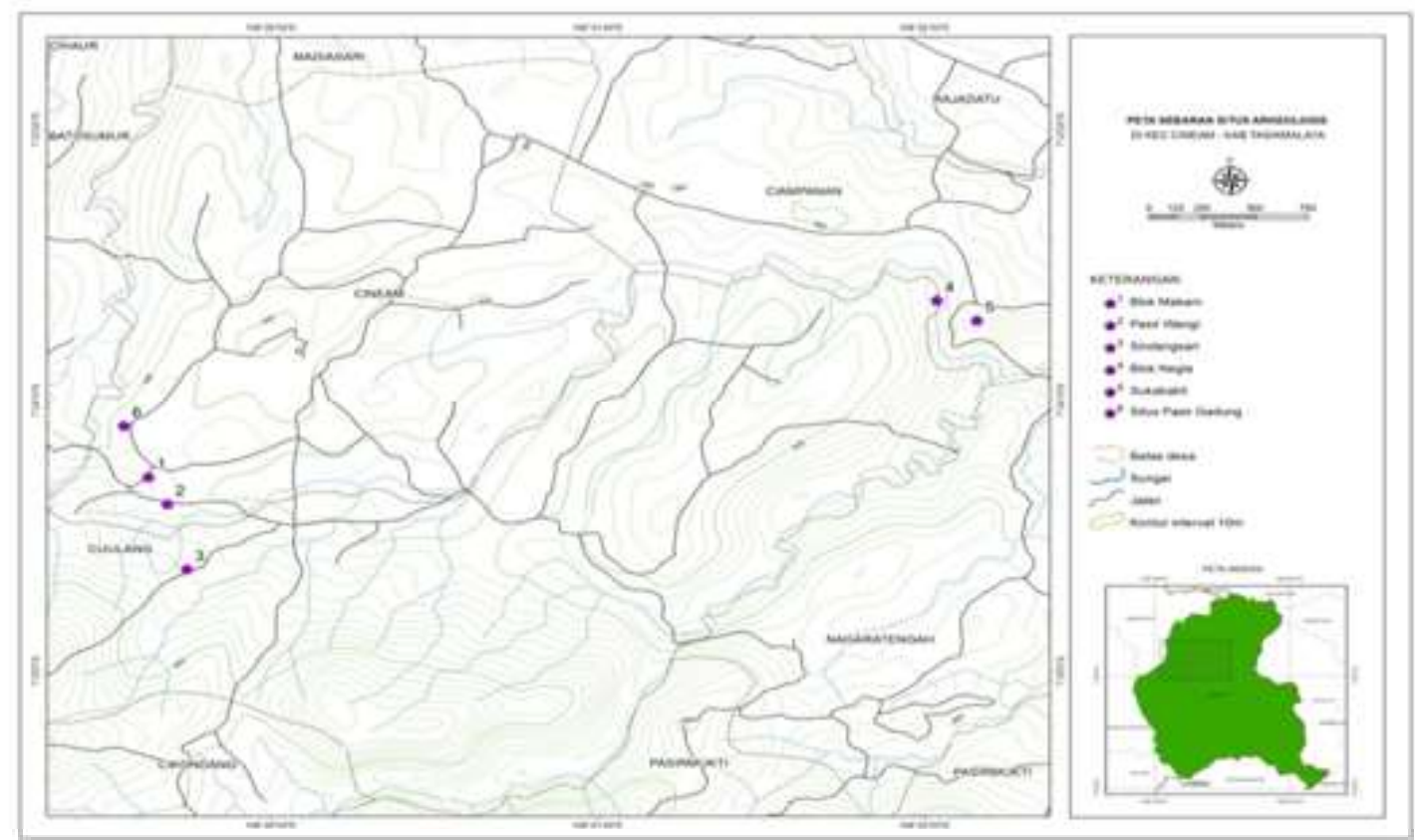

Gambar 1. Kawasan Cineam (Sumber: Laili, 2015). 


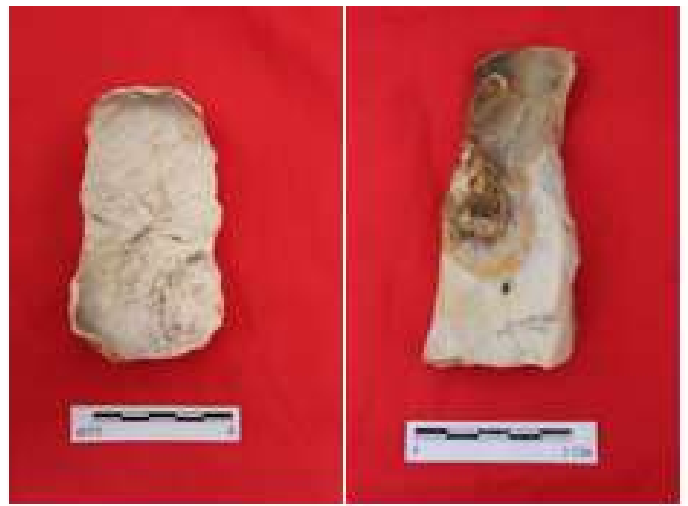

Gambar 2. Calon Beliung di Kawasan Cineam (Sumber: Dok. Balai Arkeologi Jawa Barat, 2015).

Situs-situs lain di Kawasan Cineam yaitu situs Blok Makam tinggalan neolitik berupa sebaran tatal dan tiga calon beliung, situs Sindangsari berupa sebaran tatal dan serta dua calon beliung, situs Blok Negla diperoleh sebaran tatal dan satu calon beliung. Situs lain, yaitu Sukabakti tinggalan arkeologis yang diperoleh berupa sebaran tatal dan empat calon beliung. Situs dengan tinggalan arkeologis paling sedikit adalah situs Pasirwangi dengan tinggalan berupa sebaran tatal (Gambar 3).

Situs-situs neolitik di kawasan Cibeureum secara administratif dibagi 2 wilayah, yaitu di Kecamatan Maja dan Kecamatan Curugbitung. Wilayah Kecamatan Maja terdapat 9 (sembilan) situs neolitik dan Wilayah Kecamatan Curugbitung terdapat 10 (sepuluh) situs neolitik.Keseluruhan situs secara lateral berada di sepanjang aliran sungai (Ci) Beureum.

Hasil penelitian menunjukkan bahwa situs-situs neolitik berada di tepian sungai, baik sungai utama maupun anak sungai. Situs-situs tersebut berpola mengelompok, yaitu (1.) Kelompok A, terdiri atas tiga situs yaitu Situs Kampungbaru, Jabing I, dan Jabing II. Ketiga situs berada di aliran anak sungai (Ci) Beureum. Kelompok A ini merupakan lokasi paling timur dari situssitus neolitik di kawasan Ci Beureum; (2)

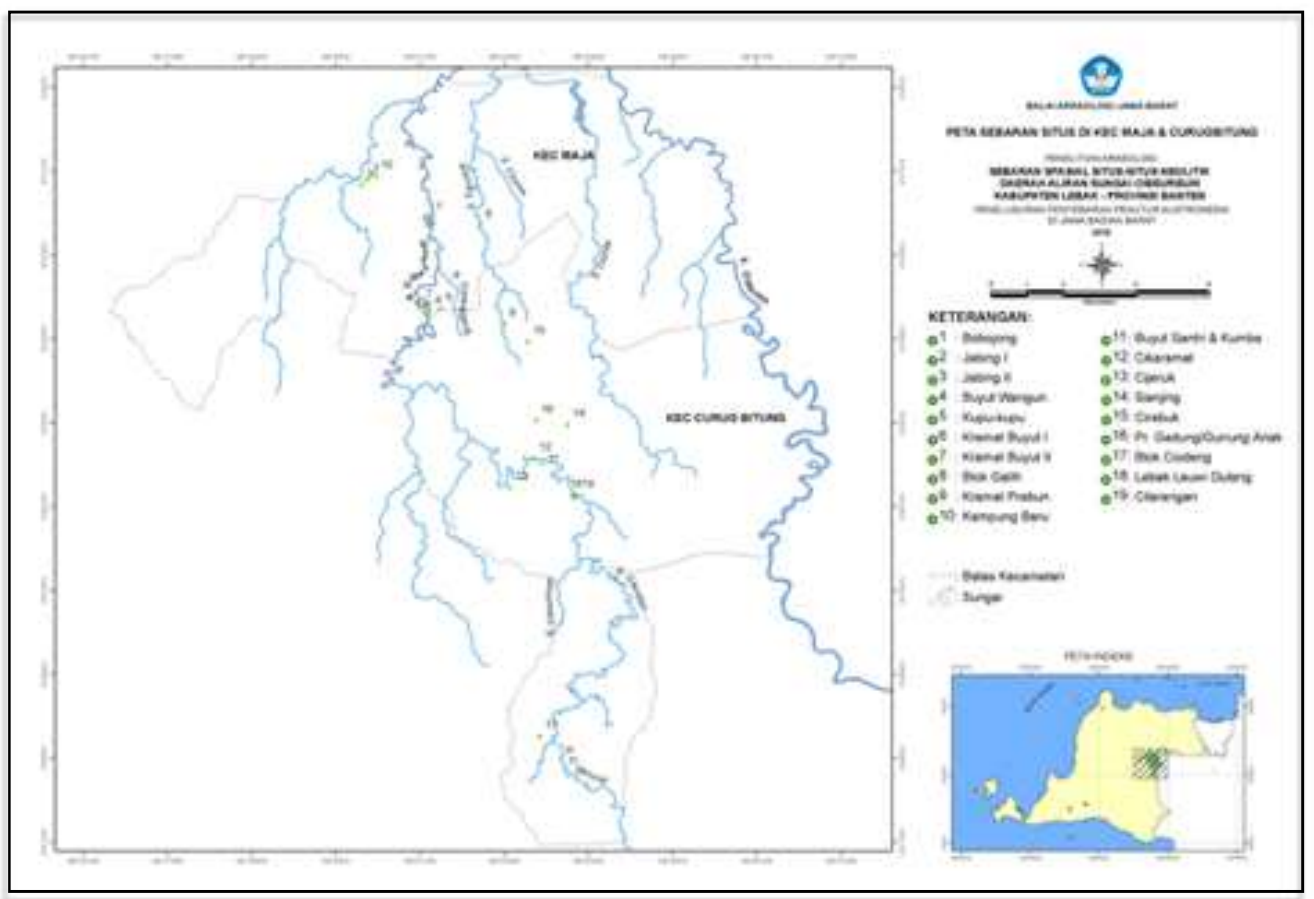

Gambar 3. Peta Kawasan Cibeureum (Sumber: Laili, 2019). 
Kelompok B berada di aliran sungai utama, yaitu Ci Beureum, lokasinya berada di sebelah timur dari Kelompok A. Situs yang berada di kelompok B terdiri atas lima situs, yaitu Bobojong, Buyut Wangun, KupuKupu, Kramat Buyut I, dan situs Kramat Buyut II; (3) Kelompok C juga berada di aliran sungai utama, yaitu $\mathrm{Ci}$ Beureum ke arah hilir. Lokasi kelompok C berada di sebelah selatan kelompok B. Situs-situs di kelompok berada di pertemuan antara $\mathrm{Ci}$ Beureum dengan anak sungainya. Situssitus yang berada di kelompok ini adalah Buyut Santri dan Kumba, Cikaramat, Cijeruk, Sianjing, dan situs Pasirgadung; (4) Kelompok D terdiri atas tiga situs yaitu Situs Blok Galih, Kramat Prebun, dan Cirebuk. Ketiga situs berada di aliran anak sungai Cibeureum, yaitu Ci Pining. Kelompok A berada di sebelah timur dari kelompok B, dan (5) Kelompok E berada paling selatan dari situs-situs yang diteliti. Pada kelompok E hanya terdiri satu situs, yaitu situs Blok Ciodeng. Situs ini berada di pertemuan anak sungai $\mathrm{Ci}$ Beureum, yaitu $\mathrm{Ci}$ Tundun dan $\mathrm{Ci}$ Gelung.

Ragam artefak yang diperoleh di kesembilan belas situs neolitik di Kawasan Cibeureum, di antaranya di situs Bobojong temuan berupa bahan berupa fosil kayu/kayu terkersikan (silicified wood), rijang (chert), jaspis, kalsedon, ditemukan di permukaan tanah (ladang) dan di sungai; situs Jabing I dan Jabing II temuan arkeologi berupa sumber bahan fosil kayu/kayu terkersikan (silicified wood), rijang (chert), jaspis, kalsedon serta tatal, serpih, dan calon beliung; situs Buyut Wangun temuan neolitik berupa bahan dari fosil kayu/kayu terkersikan (silicified wood), rijang (chert), jaspis, kalsedon, ditemukan di teras bukit. Selain bahan di situs ini juga diperoleh beliung, tatal, dan serpih; situs Kupu-Kupu berupa calon beliung, tatal, batu inti, serpih, dan bahan. Bahan tersebut berupa fosil kayu/kayu terkersikan (silicified wood), rijang (chert), jaspis, kalsedon, ditemukan di teras bukit.

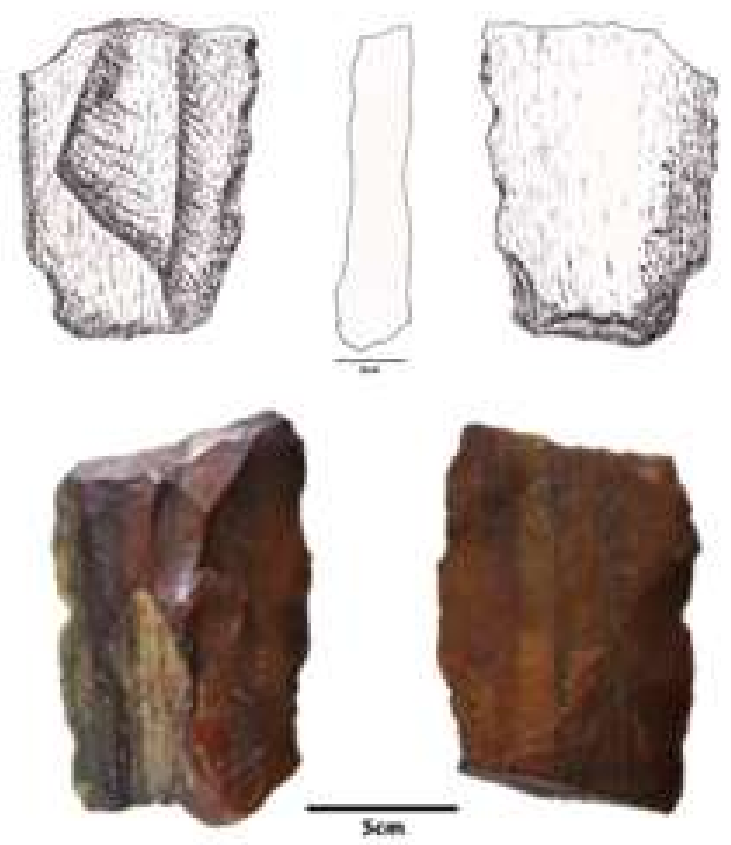

Gambar 4. Calon beliung berbahan silicified wood (Sumber: Dok, Balai Arkeologi Jabar 2019).

Situs-situs lain di Kawasan Cibeureum yang terdapat tinggalan neolitik diperoleh juga di situs Kramat Buyut I dan Kramat Buyut II. Temuan tersebut antara lain berupa calon beliung, batu inti, dan serpih. Selain itu juga terdapat bahan yang berasal dari fosil kayu/kayu terkersikan (silicified wood) dan rijang (chert); situs Blok Galih temuan neolitik berupa calon beliung, serpih, tatal, dan bahan fosil kayu, rijang, kalsedon; situs Kampung Baru temuan yang diperoleh berupa sebaran tatal dan serpih di teras sawah berbahan fosil kayu (silicified wood) dan rijang (chert); situs Buyut Santri dan Kumba temuan neolitik berupa sebaran tatal, calon beliung, dan bahan menyebar hampir di sepanjang permukaan kebun berupa fosil kayu (silicified wood) dan chert (rijang). 
Selain hal tersebut masih terdapat situs lain, diantaranya adalah situs Cikaramat. Temuan diperoleh di lahan ini berupa sumber bahan fosil kayu/kayu terkersikan (silicified wood). Hasil penelitian tahun 2005 oleh tim Balai Arkeologi Bandung memperoleh sebaran tatal dan serpih di lokasi situs (Sudarti, dkk, 2005); Situs Cijeruk temuan berupa beliung, sebaran tatal dan serpih fosil kayu; Situs Sianjing temuan neolitik berupa calon beliung, tatal, batu inti, serpih, dan bahan fosil kayu/kayu terkersikan (silicified wood), rijang (chert), jaspis, dan kalsedon.

Enam situs lain, yaitu situs Cirebuk kandungan tinggalan neolitik berupa calon beliung, serpih, tatal, dan bahan fosil kayu, rijang, kalsedon; situs Pasirgadung/Gunung Anak berdasarkan penelitian 2005 oleh tim peneliti Balai Arkeologi Bandung di situs ini diperoleh tatal dan serpih dari fosil kayu (Sudarti, dkk, 2005); Situs Blok Ciodeng temuan yang diperoleh berupa beliung dan sebaran bahan di permukaan yaitu fosil kayu (silicified wood) dan rijang (chert); Situs Leuwidulang temuan diperoleh di permukaan kebun singkong berupa sumber bahan fosil kayu/kayu terkersikan (silicified wood), rijang (chert) dan tatal serta serpih; Situs Cilarangan tinggalan arkeologi berupa sebaran bahan berupa fosil kayu/ kayu terkersikan (silicified wood) dan rijang (chert). Selain bahan di situs ini juga diperoleh beliung, batu inti, dan serpih; dan Situs Kramat Prebun dengan tinggalan arkeologi berupa bahan fosil kayu/kayu terkersikan (silicified wood)

Situs-situs neolitik baik di Kawasan Cineam maupun Kawasan Cibeureum diindikasikan sebagai lokasi dengan jejak ativitas perbengkelan. Penempatan situssitus neolitik di DAS Cibeureum mempunyai pola mengelompok. Pengelompokan situs- situs neolitik linear memanjang sejajar dengan alur sungai, yaitu Ci Beureum dan anak-anak sungainya. Demikian juga situssitus yang berada di Kawasan Cineam menempati daerah tepian sungai yaitu $\mathrm{Ci}$ Goang dan Ci Riri. Hal tersebut selaras dengan hasil penelitian Mahirta (2006), di Indonesia timur, terdapat macam pola permukiman prasejarah Austronesia yaitu permukiman berkembang memanjang ke pedalaman sejajar dengan alur sungai.

Pemilihan lokasi untuk aktivitas neolitik di Kawasan Cineam dan Kawasan Cibeureum selaras dengan teori lokasi. Suatu aktivitas dilakukan dengan mempertimbangkan tata ruang dan alokasi geografis, khususnya jarak dan aksesibilitas (Robinson, 2006). Penempatan situs neolitik di Ci Beureum, $\mathrm{Ci}$ Goang, dan Ci Riri (Ci Ampanan) menunjukkan bahwa sungai merupakan sumber air bagi manusia dan mendukung dalam aktivitas pembuatan beliung. Di antara sungai tersebut, yaitu $\mathrm{Ci}$ Goang terdapat kandungan batu rijang yang merupakan sumber bahan baku dalam aktivitas neolitik yaitu pembuatan beliung.

Sungai memiliki potensi sebagai penyedia air dan sebagai pemenuh kebutuhan masyarakat pendukung. Manusia pendukung situs bengkel memilih lokasi sepanjang daerah aliran sungai karena dapat mendukung kegiatan bengkel beliung persegi. Penentuan lokasi situs bengkel mempertimbangkan efisiensi dan efektivitas kerja.

Situs-situs bengkel yang ditempatkan di daerah aliran sungai disebabkan oleh tebing-tebing yang rendah, sungainya lebar, tidak deras, dan dangkal. Kondisi tersebut dipengaruhi oleh sungai yang berkelokkelok sehingga pengikisan tidak lagi berupa pendalaman sungai tetapi lebih ke arah samping atau tebing. Akibatnya tebing- 
tebing di daerah tersebut lebih rendah dibanding bagian hulu, sedangkan sungainya lebih lebar dibandingkan dengan daerah di atasnya atau hulu. Tingkat mobilitas manusia cenderung lebih tinggi daripada daerah hulu. Daerah hulu mempunyai tebing yang curam, aliran sungai yang deras, serta banyak jeram. Oleh karena itu, manusia pendukung bengkel tidak memilih lokasi di daerah hulu untuk aktivitasnya. Bagian hilir sungai (muara) merupakan daerah yang sering banjir sehingga daerah tersebut juga tidak dipilih oleh pendukung situs bengkel sebagai tempat aktivitasnya.

\section{SIMPULAN}

Situs-situs di Kawasan Cineam, Tasikmalaya dan Kawasan Cibeureum, Lebak berada di daerah aliran sungai, permukiman berkembang memanjang ke pedalaman sejajar dengan alur sungai. Sungai memiliki potensi sebagai penyedia air, sebagai pemenuh kebutuhan masyarakat pendukung, juga merupakan sumber penyedia bahan untuk kegiatan bengkel oleh manusia pendukung. Ci Goang dan Ci Riri di Kawasan Cineam menyediakan sumber bahan batuan berupa rijang dan kalsedon.

\section{DAFTAR PUSTAKA}

Bellwood, P. (2000). Prasejarah Kepulauan Indo-Malasyia (Revisi). PT Gramedia Pustaka Utama.

Bellwood, P. (2007). Prehistory of the IndoMalasyian Archipelago (3ed ed.). The Australian National University Press.

Laili, N. (2015). Pola Keletakan Situs-Situs Neolitik di Kawasan Cineam, Tasikmalaya. PURBAWIDYA: Jurnal Penelitian dan Pengembangan Arkeologi, Vol. 4 No., 97-108.
Laili, N. (2019). Penempatan Situs-Situs Neolitik Di Das Cibeureum Lebak Banten. Panalungtik, Vol 2. No., 77-94.

Mahirta. (2006). The Prehistory of Austronesian Dispersal to the Southern Islands of Eastern Indonesia. In T. dkk Simanjuntak (Ed.), Proceedings of the International Symposium Austronesian Diaspora and The Ethnogeneses of People in Indonesian Archipelago (hal. 141-145). LIPI.

Noerwidi, S dan Priyanto, H. (2011). Awal Kolonisasi Austronesia di Tenggara Pulau Jawa: Perspektif Situs Kendenglembu. Amerta, Vol,29. No, 45-60.

Robinson, T. (2006). Ekonomi Regional: Teori dan Aplikasinya (Revisi). Bumi Aksara.

Simanjuntak, T. (1992). Neolitik di Indonesia: Neraca dan Perspektif Penelitian. Jurnal Arkeologi Indonesia. Jurnal Arkeologi Indonesia No. 1, 117-130.

Simanjuntak, T. (2015). Progres Penelitian Austronesia Di Nusantara. Amerta, 33(1), 25. https://doi.org/10.24832/ amt.v33i1.211

Sudarti, D. (2005). Pola Persebaran Situs-Situs Religi di Kecamatan Curugbitung, Kabupaten Lebak, Provinsi Banten. Bandung: Balai Arkeologi Jawa Barat

\section{HASIL DISKUSI}

\section{Pertanyaan}

\section{Budianto Hakim (Balai Arkeologi Sulawesi Selatan)}

Adanya keraguan untuk mengambil sampel dating situs Lebak dan Tasikmalaya. Seharusnya jangan ragu karena diambil dari lapisan tanah yang tidak terganggu. Apakah tadi yang 
dianggap tatal tersebut benar tatal atau serpih? Tidak menutup kemungkinan Austronesia dapat memproduksi alat serpih mengadopsi teknologi dari pendahulunya. Contohnya beberapa lokasi yang diekskavasi di Sulawesi masih menemukan serpih. Mungkin ada pertemuan dengan non-Austronesia di mana mereka saling tukar informasi teknologi.

\section{Jawaban}

1. Nurul Laili, S.S. (Balai Arkeologi Jawa Barat)

Peneliti akan coba menganalisis dengan lebih detail. 